\title{
A Radiation Safety Training Program Results in Reduced Radiation Exposure for Orthopaedic Residents Using the Mini C-arm
}

\author{
David Gendelberg MD, William Hennrikus MD, Jennifer Slough MD, \\ Douglas Armstrong MD, Steven King PhD
}

Received: 11 June 2015/Accepted: 5 November 2015/Published online: 13 November 2015

(C) The Association of Bone and Joint Surgeons (B) 2015

\begin{abstract}
Background Fluoroscopy during fracture reduction allows a physician to assess fractures and immediately treat a pediatric patient. However, concern regarding the effects of radiation exposure has led us to find ways to keep radiation exposures as low as reasonably achievable. One potentially simple way, which to our knowledge has not been explored, to decrease radiation exposure is through formal education before mini C-arm use.

Questions/purposes We questioned whether a radiation safety educational program decreases radiation (1) time and (2) exposure among residents and patients.
\end{abstract}

\footnotetext{
Each author certifies that he or she, or a member of his or her immediate family, has no funding or commercial associations (eg, consultancies, stock ownership, equity interest, patent/licensing arrangements, etc) that might pose a conflict of interest in connection with the submitted article.

All ICMJE Conflict of Interest Forms for authors and Clinical Orthopaedics and Related Research ${ }^{\circledR}$ editors and board members are on file with the publication and can be viewed on request.

Each author certifies that his or her institution approved or waived approval for the human protocol for this investigation and that all investigations were conducted in conformity with ethical principles of research.

This study was performed at Penn State Hershey Medical Center, Hershey, PA, USA.
}

D. Gendelberg $(\bowtie)$, W. Hennrikus, D. Armstrong Department of Orthopaedics, Penn State Hershey Medical Center, 500 University Drive, Hershey, PA 17033, USA

e-mail: dgendelberg@hmc.psu.edu

J. Slough

Penn State Hershey College of Medicine, Hershey, PA, USA

S. King

Department of Radiology and Health Physics, Penn State Hershey Medical Center, Hershey, PA, USA
Patients and Methods This is a retrospective study in which second-year residents underwent a 3-hour educational program regarding mini $\mathrm{C}$-arm use and radiation safety taught by our institution's health physics department. We evaluated the records of all patients who underwent a pediatric both-bone forearm or distal radius fracture reduction in the emergency department 3 months before the educational program or after the program. To be included in the study, records included simple both-bone forearm fractures, simple distal radius fractures, and patient age younger than 18 years, and could not include patients with multiple fractures in the same limb. This resulted in study groups of 53 and 45 patients' records in the groups before and after the educational session, respectively. Radiation emission from the mini C-arm between both groups were compared.

Results Exposure time with the mini C-arm was longer in patients treated before the educational intervention than in those treated after the intervention (patients with both-bone forearm fractures: mean $=41.2, \mathrm{SD}=24.7,95 \% \mathrm{CI}, 23.14$ 59.26 vs mean $=28.9, \mathrm{SD}=14.4,95 \% \mathrm{CI}, 15.91-41.89$, $\mathrm{p}=0.066$; patients with distal radius fractures: mean $=$ $38.1, \mathrm{SD}=26.1,95 \% \mathrm{CI}, 25.1-51.1$ vs mean $=26.7, \mathrm{SD}=$ 15.8, 95\% CI, 16.44-36.96, $\mathrm{p}=0.042)$. Calculated radiation exposure with the mini $\mathrm{C}$-arm was larger in patients treated before the educational intervention than in those treated after the intervention (patients with both-bone forearm fractures: mean $=90.9, \mathrm{SD}=60.9,95 \% \mathrm{CI}, 51.06$ 130.74 vs mean $=30.4, \mathrm{SD}=18.5,95 \% \mathrm{CI}, 16.73-44.07$, $\mathrm{p}<0.001$; patients with distal radius fractures: mean $=$ 83.1, $\mathrm{SD}=58.9,95 \% \mathrm{CI}, 54.75-111.45$ vs mean $=32.6$, $\mathrm{SD}=26.4,95 \% \mathrm{CI}, 20.07-45.13, \mathrm{p}<0.001)$.

Conclusions A radiation-safety program resulted in decreased radiation exposure to residents and patients, and 
in decreased mini $\mathrm{C}$-arm exposure time during pediatric fracture reductions.

Level of Evidence Level III, therapeutic study.

\section{Introduction}

The mini C-arm fluoroscope is a commonly used tool for pediatric fracture reduction in the emergency department, and because of this, radiation safety has become a topic of interest $[5,9,10,15]$. Mastrangelo et al. [12] suggested that orthopaedic surgeons in a hospital with poor radiation protection had a substantially greater incidence of cancer. The concern regarding the effects of radiation exposure has led to the use of ALARA (as low as reasonably achievable) techniques with healthcare workers [7]. According to the National Council on Radiation Protection and Standards, the recommended maximum annual dose of radiation to the whole body is $5000 \mathrm{mR}$ and 50,000 $\mathrm{mR}$ to the extremities [20].

Radiation safety has taken on a central role in the American Board of Orthopaedic Surgeons surgical skills curriculum for residents [19]. The importance of radiation safety is essential as radiation exposure is cumulative for the resident throughout his or her career. Research suggests that technique and experience matter when it comes to radiation safety; more junior residents received greater radiation exposure than did more-experienced residents [18], suggesting that good habits in this regard can be taught. However, to our knowledge, no research evaluating the effectiveness of formal education exists regarding radiation safety use on radiation exposure among residents. Therefore, we sought to investigate the radiation exposure and radiation time for residents in the emergency department, after undergoing a radiation safety program, when reducing both-bone forearm and distal radius fractures in the pediatric population. The residents had no prior training in mini C-arm safety.

We asked: (1) Does a radiation safety educational program decrease radiation time among residents, and (2) does a radiation safety educational program decrease radiation exposure among residents and patients.

\section{Patients and Methods}

\section{Study Design and Setting}

This is a retrospective study of radiation exposure times and amount of whole body radiation incurred by the patient and resident performing the reduction. Fifty-three pediatric patients who underwent fracture reductions during the 3 months immediately before the educational program were compared with 45 pediatric patients with isolated and displaced both-bone forearm and distal radius fracture reduction in the emergency department during the 3 months immediately after undergoing the program. No isolated fractures that underwent reduction in the emergency department were excluded. The study was performed at an academic, Level 1, pediatric and adult trauma center.

\section{Participants/Study Subjects}

The study proposal was reviewed and authorized by our institution's institutional review board. The study subjects were second-year residents who were on call in the emergency department before and after the educational session. The group before the intervention consisted of second-year residents toward the end of their academic year whereas the group after the intervention consisted of second-year residents at the beginning of their academic year. The inclusion criteria for the study included simple both-bone forearm fractures and simple distal radius fractures requiring reduction, in patients younger than 18 years, within a 3-month period before and after the educational session.

\section{Description of Experiment, Treatment, or Surgery}

All residents in the orthopaedic department underwent a formal 3-hour educational program regarding mini C-arm use and radiation safety which was taught by our institution's health physics department. The program began with a 2-hour lecture encompassing radiation physics, how the mini C-arm works, and the different safety measures one could take to decrease radiation exposure. After the lecture the residents were able to practice using the mini C-arm with the help of models and Geiger counters to affirm the principles taught in the lecture. In addition, the residents were able to continue practicing mini $\mathrm{C}$-arm use in a controlled setting with supervision.

Variables, Outcome Measures, Data Sources, and Bias

To answer the first question regarding whether a radiation safety educational program decreases radiation exposure time among residents and patients, radiation exposure times to the patient and resident performing the fracture reductions were recorded from the mini C-arm. Data from 53 pediatric patients during 3 months immediately before the educational program were compared with data from 45 pediatric patients undergoing both-bone forearm and distal radius fracture reduction in the emergency department during the 3 months immediately after undergoing the program. 
To answer the second question regarding whether a radiation safety educational program decreases radiation exposure among residents and patients, radiation emission from the mini $\mathrm{C}$-arm was calculated based on the parameters recorded by the mini $\mathrm{C}$-arm. Data from 53 pediatric patients during 3 months immediately before the educational program were compared with data from 45 pediatric patients undergoing both-bone forearm and distal radius fracture reduction in the emergency department during the 3 months immediately after undergoing the program.

Images during fracture reduction were obtained using the mini C-arm (Fluoroscan InSight; Hologic Inc, Bedford, MA, USA). The mini $\mathrm{C}$-arm recorded the amount of kilovolts, milliamps, and the number of seconds that the foot pedal was used. Radiation emission from the mini Carm was calculated by a radiation physicist (SK) using these parameters. All reductions were acceptable and approved by the pediatric orthopaedic attending on call.

\section{Statistical Analysis, Study Size}

Statistical analyses were performed with data expressed as the mean radiation time and exposure $\pm 95 \%$ CI with associated standard deviation. Normality analysis found the data to be normally distributed. Therefore, the Student's t-test was used and results were reported to be significant with a probability less than 0.05 .

\section{Demographics, Description of Study Population}

The radiation incurred during 98 fractures was examined. Fifty-three fractures were reduced in the group before the educational session and 45 in the group after intervention. The average age of the patients in the group before intervention was 9.6 years compared with 9.5 years in the group after the educational session. Of the 53 patients in the first group, 31 were male, 22 were female, 20 had both-bone forearm fractures, and 33 had distal radius fractures. Of the 45 patients in the second group, 32 were male, 13 were female, 19 had both-bone forearm fractures, and 26 had distal radius fractures.

\section{Results}

Exposure time with the mini $\mathrm{C}$-arm was longer in patients treated before the educational intervention than in those treated after the intervention (patients with both-bone forearm fractures: mean $=41.2, \mathrm{SD}=24.7,95 \% \mathrm{CI}, 23.14$ 59.26 vs mean $=28.9, \mathrm{SD}=14.4,95 \% \mathrm{CI}, 15.91-41.89, \mathrm{p}$ $=0.066$; patients with distal radius fractures: mean $=38.1$,
$\mathrm{SD}=26.1,95 \% \mathrm{CI}, 25.1-51.1$ vs mean $=26.7, \mathrm{SD}=15.8$, 95\% CI, 16.44-36.96, $\mathrm{p}=0.042$ ).

Calculated radiation exposure with the mini $\mathrm{C}$-arm was larger in patients treated before the educational intervention than in those treated after the intervention (patients with both-bone forearm fractures: mean $=90.9, \mathrm{SD}=60.9$, 95\% CI, 51.06-130.74 vs mean $=30.4, \mathrm{SD}=18.5,95 \% \mathrm{CI}$, 16.73-44.07, $\mathrm{p}<0.001$; patients with distal radius fractures: mean $=83.1, \mathrm{SD}=58.9,95 \% \mathrm{CI}, 54.75-111.45 \mathrm{vs}$ mean $=32.6, \mathrm{SD}=26.4,95 \% \mathrm{CI}, 20.07-45.13, \mathrm{p}<0.001)$ (Table 1).

\section{Discussion}

The use of the mini C-arm is a useful adjunct in pediatric fracture reduction in the emergency department, but there are risks to using it, including operator variability and radiation exposure, which may result in skin burns, nausea, or potentially an increased risk of malignancy. Although the relationship between diagnostic medical imaging radiation exposure and solid and hematologic malignancy is controversial, it is still prudent to minimize exposure [4, 11]. To our knowledge, no one has evaluated whether education regarding radiation exposure when using the mini C-arm improved safety. We therefore evaluated $\mathrm{C}$-arm time and calculated radiation dosage emitted by the mini C-arm during the course of closed reductions performed by residents in the emergency room. We found that after a 3-hour educational session regarding mini $\mathrm{C}$-arm use, the residents were able to reduce radiation time and exposure while reducing both-bone forearm and distal radius fractures. We believe that a structured radiation safety program is important in limiting radiation exposure during residency and beyond.

The Pediatric Orthopaedic Society of North America has made implementation of its Quality, Safety, and Value Initiative (QSVI) a high priority. The initiative's goal is to coordinate between institutions and implement a unified program for the improvement of quality of care and safety while delivering value (Value = Outcome/Cost) [14]. Radiation safety in particular is a QSVI priority [13, 21]. We sought to evaluate the radiation safety and effect on the value of the mini $\mathrm{C}$-arm. Specifically, in this study, we evaluated the change in radiation exposure to residents and patients when using the mini $\mathrm{C}$-arm after undergoing training by a radiation physicist regarding its use.

The British Columbia Centre for Disease Control determined that lead aprons and personal monitoring of radiation exposure were not required at distances greater than $1 \mathrm{M}$ from the image intensifier [3]. In the current study the resident needed to stand close to the mini C-arm to hold the child's limb for imaging. Therefore, we recommend 


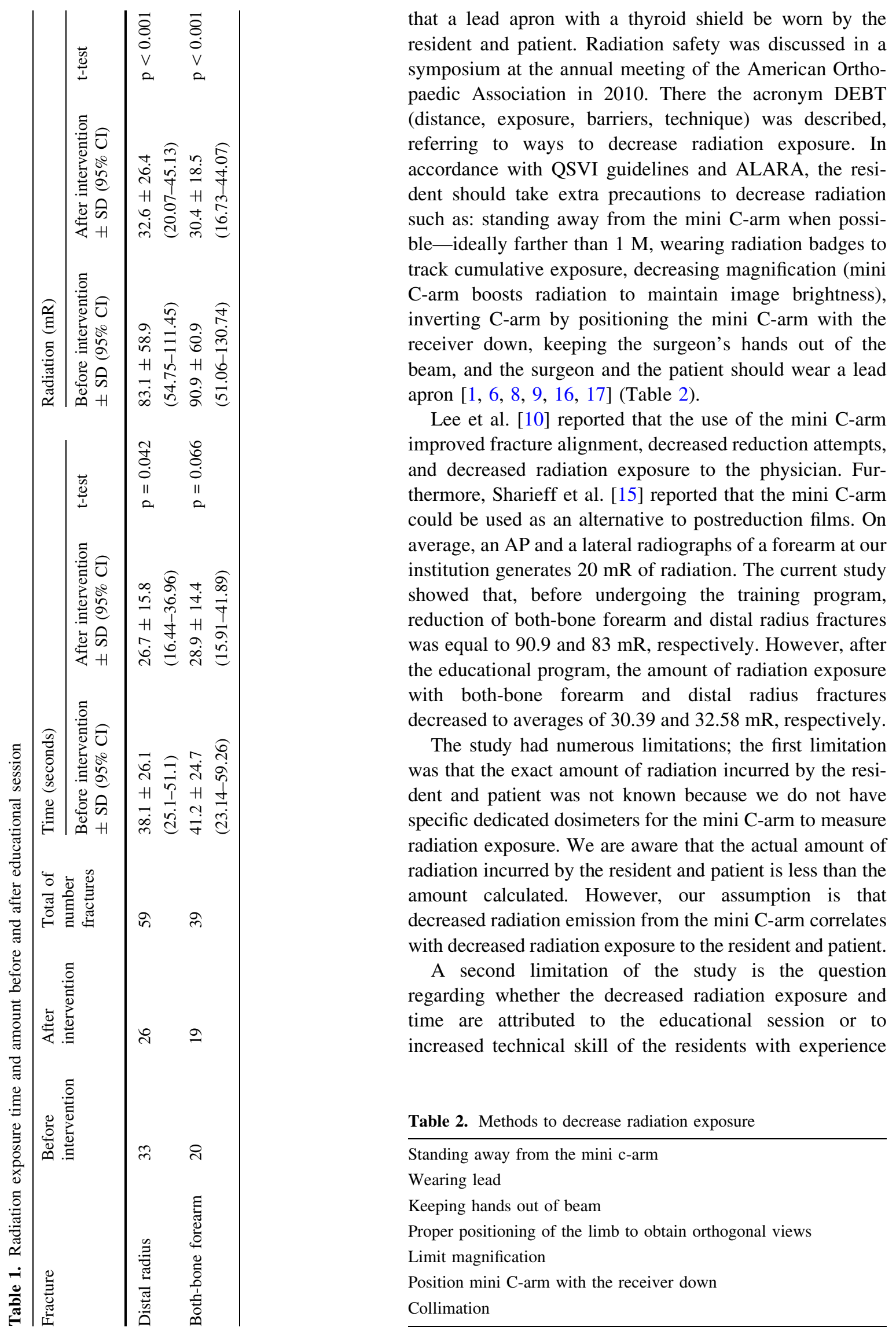


and repetition. To help minimize experience as a confounding variable, both groups were chronologically continuous. In addition, patients treated after the educational intervention were treated during the summer when there was a new class of second-year residents with less experience than the first group which consisted of outgoing second-year residents.

There was a decrease in reduction time for distal radius fractures, although with the numbers available, there was no decrease in radiation time in both-bone forearm fracture reduction; the latter finding may have been from insufficient statistical power. It is important to find ways to decrease radiation exposure. Badman et al. [2] showed that at any given position or situation, the mini C-arm was preferable to the regular $\mathrm{C}$-arm in terms of radiation exposure and should be used whenever available. We sought to find additional ways to decrease radiation exposure, and our study showed that an educational program regarding mini $\mathrm{C}$-arm use is beneficial in decreasing radiation exposure among residents and patients. We found there was a large decrease in radiation exposure for distal radius and both-bone forearm fracture reductions when comparing residents before and after mini $\mathrm{C}$-arm training.

We chose to focus on the simple pediatric upper extremity fractures which tend to be in some ways the bestcase scenario for limited radiation exposure given the limb size and relative flexibility of most patients. Therefore, the benefits in other, more complex, settings may be larger than those observed in our study.

The use of the mini $\mathrm{C}$-arm is a useful adjunct to pediatric fracture reduction in the emergency department. We found that a 3-hour educational session regarding mini C-arm use helped residents reduce radiation time and exposure while reducing both-bone forearm and distal radius fractures. We believe that a structured radiation safety program plays an important role in limiting radiation exposure during residency and beyond. We recommend mini C-arm training for all physicians and staff who use this tool. In future studies it would be beneficial to assign a specific dosimeter to be used with the mini $\mathrm{C}$-arm to evaluate the exact amount of radiation incurred by the resident. In addition, we currently are working on a followup study evaluating whether the educational program has a persistent benefit in the long run.

\section{References}

1. Agarwal A. Radiation risk in orthopedic surgery: ways to protect yourself and the patient. Oper Techn Sports Med. 2011;19:220223.

2. Badman BL, Rill L, Butkovich B, Arreola M, Griend RA. Radiation exposure with use of the mini-c-arm for routine orthopaedic imaging procedures. J Bone Joint Surg Am. 2005;87:13-17.

3. Duran EB, Phillips B. Occupational exposures during mini C-arm medical procedures. British Columbia Centre for Disease Control.
Available at: http://www.bccdc.ca/NR/rdonlyres/4EBD0249-5FAB4D57-90E9-8D0B63C66E22/0/Occ_Exp_MiniCarm_Med_Proc.pdf. Accessed September 2, 2015.

4. Fabricant PD, Berkes MB, Dy CJ, Bogner EA. Diagnostic medical imaging radiation exposure and risk of development of solid and hematologic malignancy. Orthopedics. 2012;35:415-420.

5. Giordano BD, Baumhauer JF, Morgan TL, Rechtine GR 2nd. Patient and surgeon radiation exposure: comparison of standard and mini Carm fluoroscopy. J Bone Joint Surg Am. 2009;91:297-304.

6. Giordano BD, Ryder S, Baumhauer JF, DiGiovanni BF. Exposure to direct and scatter radiation with use of mini c-arm fluoroscopy. J Bone Joint Surg Am. 2007;89:948-952.

7. Hall EJ, Brenner DJ. Cancer risks from diagnostic radiology. $\mathrm{Br} \mathrm{J}$ Radiol. 2008;81:362-378.

8. International Commission on Radiological Protection. The 2007 recommendations of the International Commission on Radiological Protection. ICRP publication 103. Ann ICRP. 2007;37:1-332.

9. Lee MC, Stone NE 3rd, Ritting AW, Siverstein EA, Pierz KA, Johnson DA, Naujoks R, Smith BG, Thomson JD. Mini-C-arm fluoroscopy for emergency-department reduction of pediatric forearm fractures. J Bone Joint Surg Am. 2011;93:1442-1447.

10. Lee SM, Orlinski M, Chan LS. Safety and effectiveness of portable fluoroscopy in the emergency department for the management of distal extremity fractures. Ann Emerg Med. 1994; 24:725-730.

11. Lin EC. Radiation risk from medical imaging. Mayo Clinic Proc. 2010;85:1142-1146.

12. Mastrangelo G, Fedeli U, Fadda E, Giovanazzi A, Scoizzato L, Saia B. Increased cancer risk among surgeons in an orthopaedic hospital. Occup Med (Lond). 2005;55:498-500.

13. McCarthy JJ. POSNA puts quality, safety, value in action: QSVI is 3 years old and growing strong. AAOS Now. 2013. Available at: http://www.aaos.org/news/aaosnow/dec13/research6.asp. Accessed November 2, 2015.

14. Porter ME. What is value in health care? N Engl J Med. 2010; 363:2477-2481.

15. Sharieff GQ, Kanegaye J, Wallace CD, McCaslin, RI, Harley JR. Can portable bedside fluoroscopy replace standard, post reduction radiographs in the management of pediatric fractures? Pediatr Emerg Care. 1999;15:249-251.

16. Sherbini S, DeCicco J. Estimation of the effective dose when protective aprons are used in medical procedures: a theoretical evaluation of several methods. Health Phys. 2002; 83: 861-870.

17. Singer G. Occupational radiation exposure to the surgeon. $J A m$ Acad Orthop Surg. 2005;13:69-76.

18. Sumko MJ, Hennrikus W, Slough J, Jensen K, Armstrong D, King S, Urish K. Measurement of radiation exposure when using the mini c-arm to reduce pediatric upper extremity fractures. J Pediatr Orthop. 2015 Feb 26. [Epub ahead of print].

19. The American Board of Orthopaedic Surgery. ABOS Surgical Skills Modules for PGY-1 Residents. Available at: https://www. abos.org/abos-surgical-skills-modules-for-pgy-1-residents.aspx. Accessed September 2, 2015.

20. United States Nuclear Regulatory Commission. § 20.1201 Occupational dose limits for adults. Available at: http://www.nrc. gov/reading-rm/doc-collections/cfr/part020/part020-1201.html. Accessed October 3, 2015.

21. Vitale MG, Riedel MD, Glotzbecker MP, Matsumoto H, Roye DP, Akbarnia BA, Anderson RC, Brockmeyer DL, Emans JB, Erickson M, Flynn JM, Lenke LG, Lewis SJ, Luhmann SJ, McLeod LM, Newton PO, Nyquist AC, Richards BS 3rd, Shah SA, Skaggs DL, Smith JT, Sponseller PD, Sucato DJ, Zeller RD, Saiman L. Building consensus: development of a Best Practice Guideline (BPG) for surgical site infection (SSI) prevention in high-risk pediatric spine surgery. J Pediatr Orthop. 2013;33:471478 . 